\title{
BMJ Open Association between haemorrhoids and Graves' disease: a retrospective cohort study using data from Taiwan's Longitudinal Health Insurance Database
}

\author{
Shang-Rong Zhong, ${ }^{1}$ Hsin-Hung Chen, ${ }^{2}$ Chun-Cheng Liao (D , ${ }^{1}$ Chun-Hung Su, ${ }^{3}$ \\ Hei-Tung Yip,, ${ }^{4,5}$ Chia-Hung Kao (iD) ${ }^{6,7,8,9}$
}

To cite: Zhong S-R, Chen $\mathrm{H}-\mathrm{H}$, Liao C-C, et al. Association between haemorrhoids and Graves' disease: a retrospective cohort study using data from Taiwan's Longitudinal Health Insurance Database. BMJ Open 2021;11:e053442. doi:10.1136/ bmjopen-2021-053442

- Prepublication history for this paper is available online. To view these files, please visit the journal online (http://dx.doi org/10.1136/bmjopen-2021053442).

Received 13 May 2021 Accepted 06 December 2021

Check for updates

(c) Author(s) (or their employer(s)) 2021. Re-use permitted under CC BY-NC. No commercial re-use. See rights and permissions. Published by BMJ.

For numbered affiliations see end of article.

Correspondence to

Dr Chia-Hung Kao;

d10040@mail.cmuh.org.tw

\section{ABSTRACT}

Objective To evaluate the relationship between

haemorrhoids and Graves' disease (GD).

Setting Using the nationwide data from Taiwan's Longitudinal Health Insurance Database.

Participants We conducted a retrospective study, stratified patients by International Classification of Diseases, Ninth Revision, Clinical Modification disease code and compared the incidence rate of GD between patients with and without haemorrhoids. The study period was from 2000 to 2010, with exclusion of patients with diagnosed haemorrhoids before 2000 or after 2009, and we analysed the HR of GD in the univariable and multivariable models as well as the cumulative incidence curves of GD by using KaplanMeier curves.

Result This study included 13165 and 52660 patients with and without haemorrhoids, respectively. The mean follow-up duration was approximately 6 years. The incidence rate of GD was 1.57 and 1.13 per 1000 person-years in patients with and without haemorrhoids, respectively. The area under the cumulative incidence curve of GD in patients with haemorrhoids was higher than that of patients without haemorrhoids. The risk of GD increased by 1.39 times $(95 \% \mathrm{Cl} 1.13$ to 1.71$)$ in patients with haemorrhoids compared with patients without haemorrhoids. In the subgroup analysis, women with haemorrhoids had a higher risk of GD (adjusted HR 1.44; 95\% $\mathrm{Cl} 1.13$ to 1.83). Patients with haemorrhoids aged $30-39$ years were more likely to develop GD (adjusted HR 1.73; $95 \% \mathrm{Cl} 1.18$ to 2.55 ).

Conclusion The findings of this study indicate that patients with haemorrhoids may have an increased risk of GD compared with other potential confounding factors.

\section{INTRODUCTION}

Haemorrhoids are commonly diagnosed on routine health examination, ${ }^{1}$ and its prevalence has been increasing. The potential risk factors for haemorrhoids include male sex, age $<40$ years, improper diet, stress, depression, high body mass
Strengths and limitations of this study

- Data for haemorrhoids, Graves' disease and other comorbidities were retrieved only from the International Classification of Diseases, Ninth Revision, Clinical Modification codes, which are input by the doctor without strict surveillance.

- We could not obtain certain critical parameters, because of restrictions or unavailability of the relevant information in the database.

- This data analysis of this study revealed the association between the two diseases that was not mentioned directly in the literature to our knowledge.

- Potential confounders like constipation, diabetes and depression were discussed, yet other unmeasured confounding factors were still not identified.

index, abdominal obesity, pregnancy and increased intra-abdominal pressure. $^{2-5}$ Although $40 \%$ of patients with haemorrhoids are asymptomatic, others may experience rectal bleeding, painful perianal mass, prolapse, faecal incontinence and perianal fullness and irritation. In the USA, haemorrhoid is the fourth leading gastrointestinal disorder diagnosed in outpatient visits, accounting for approximately $4.4 \%$ of the overall population. ${ }^{6}$ The estimated cost of this disease in the employer-insured population was approximately US\$800 million in 2014, with a substantial increasing trend. ${ }^{7}$

Graves' disease (GD) is an autoimmune disease characterised by abnormal amounts of circulating antibodies that bind to and activate thyrotropin receptors, thus causing hyperthyroidism. It is the most common cause of hyperthyroidism in children and is associated with ophthalmopathy, goitre and dermopathy. Patients with GD typically present with bulging eyes, vision loss, enlarged thyroid, pretibial myxoedema and 
other signs of thyrotoxicosis such as palpitations, tremulousness and anxiety. ${ }^{8}$ Risk factors include female sex, stress, pregnancy, younger age, smoking, heredity and history of other autoimmune disorders. ${ }^{1011}$ Global variation in the epidemiology of hyperthyroidism was observed due to differences in population, diagnostic thresholds and iodine nutrition. ${ }^{12}$ A US retrospective study reported the incidence of GD to be 30 per 100000 persons per year from 1935 to $1967 .^{13}$

Our previous work found an increased risk of Hashimoto's thyroiditis, an autoimmune thyroid disease (AITD), in patients with haemorrhoids. ${ }^{14}$ No study has evaluated the correlation between haemorrhoids and GD, another AITD. In this study, we analysed the association between haemorrhoids and GD by using Taiwan's National Health Insurance (NHI) Research Database (NHIRD).

\section{METHODS}

\section{Study population}

Since 1995, Taiwan's NHI programme has $>99 \%$ of the Taiwanese population, which consists of $98 \%$ of Han ethnicity. The original claims data are stored in the NHIRD. For privacy, the identification data are encrypted. Patients aged $\geq 18$ years with at least two outpatient and one admission record of haemorrhoids, as defined using the International Classification of Diseases, Ninth Revision, Clinical Modification (ICD-9-CM) disease codes $455.1-455.5$ and 455.8 were included as the study group. People without haemorrhoids were enrolled in the control group. The study period was 2000-2010. Patients with haemorrhoids diagnosed before 2000 or after 2009 and those already diagnosed with GD before entering the study were excluded. Patients with and without haemorrhoids were matched by sex, age and comorbidities at a ratio of $1: 4$ by propensity score matching.

\section{Main outcome and comorbidities}

The incidence of GD (ICD-9-CM code 242.0) was considered the primary event in this study. Patients who were lost to follow-up or died were censored. The potential confounders were coronary artery disease (CAD; ICD9-CM codes 410-414), heart failure (ICD-9-CM codes 428), diabetes (ICD-9-CM codes 250), depression (ICD9-CM codes 296.2, 296.3, 300.4 and 311), stroke (ICD9-CM codes 430-438), hypertension (ICD-9-CM codes 401-405), hyperlipidaemia (ICD-9-CM codes 272), CKD (ICD-9-CM codes 580-589) and constipation (ICD-9-CM codes 564.0).

\section{Statistical analysis}

Baseline characteristics between patients with and without haemorrhoids are examined by a standard mean difference (SMD). SMD $<0.1$ was considered to indicate a negligible difference. The Cox
Table 1 Baseline characteristics of patients with and without haemorrhoids

\begin{tabular}{|c|c|c|c|c|c|}
\hline \multirow[b]{3}{*}{ Variables } & \multicolumn{4}{|c|}{ Haemorrhoids } & \multirow[b]{3}{*}{ SMD } \\
\hline & \multicolumn{2}{|c|}{$\begin{array}{l}\text { No } \\
(N=52660)\end{array}$} & \multicolumn{2}{|c|}{$\begin{array}{l}\text { Yes } \\
(N=13165)\end{array}$} & \\
\hline & $n$ & $\%$ & $n$ & $\%$ & \\
\hline Gender & & & & & 0.01 \\
\hline Female & 22995 & 44 & 5688 & 43 & \\
\hline Male & 29665 & 56 & 7477 & 57 & \\
\hline \multicolumn{6}{|l|}{ Age, year } \\
\hline $18-29$ & 7536 & 14 & 1888 & 14 & 0.001 \\
\hline $30-39$ & 10645 & 20 & 2684 & 20 & 0.004 \\
\hline $40-49$ & 12182 & 23 & 3082 & 23 & 0.01 \\
\hline$\geq 50$ & 22297 & 42 & 5511 & 42 & 0.01 \\
\hline Mean, (SD) & 48.5 & (16.8) & 48.2 & (16.5) & 0.02 \\
\hline \multicolumn{6}{|l|}{ Comorbidities } \\
\hline CAD & 1271 & 2.4 & 39 & 3.0 & 0.04 \\
\hline Heart failure & 1773 & 3.4 & 500 & 3.8 & 0.02 \\
\hline DM & 6587 & 13 & 1687 & 13 & 0.01 \\
\hline Depression & 3934 & 7.5 & 1023 & 7.8 & 0.01 \\
\hline Stroke & 4483 & 8.5 & 1213 & 9.2 & 0.03 \\
\hline Hypertension & 14612 & 28 & 3640 & 28 & 0.002 \\
\hline Hyperlipidaemia & 10525 & 20 & 2635 & 20 & 0.001 \\
\hline CKD & 2817 & 5.4 & 782 & 5.9 & 0.03 \\
\hline Constipation & 12545 & 24 & 3114 & 24 & 0.004 \\
\hline
\end{tabular}

Follow-up: control: 5.87(2.87) case: 5.86(2.89).

CAD, coronary artery disease; CKD, chronic kidney disease; DM, diabetes mellitus; SMD, standard mean difference.

proportional-hazards model was used to estimate the risk of GD. The univariable model was used to estimate the crude HR, and the multivariable model, which involved variables of sex, age, depression and hypertension, was used to estimate the adjusted HR. The cumulative incidence curves were obtained using the Kaplan-Meier method and assessed using the logrank test. Statistical analysis was performed using SAS (V.9.1, SAS Institute). A two-tailed $\mathrm{p}<0.05$ was set as significant.

There was no patient or public involvement.

\section{RESULTS}

We recruited 13165 patients with haemorrhoids and 52660 patients without haemorrhoids. The mean follow-up duration was approximately 6 years. Table 1 presents the participants' baseline characteristics. They were mainly men and aged over 50 . The distribution of comorbidities in patients with and without haemorrhoids was similar (all SMDs $<0.1$ ).

As presented in table 2, the incidence rate of GD in patients with haemorrhoids was 1.57 per 1000 person-years 
Table 2 Incidence rate and HR of Graves' disease

\begin{tabular}{|c|c|c|c|c|c|c|c|}
\hline \multirow[b]{2}{*}{ Variables } & \multicolumn{3}{|c|}{ Graves' disease } & \multirow[b]{2}{*}{ cHR } & \multirow[b]{2}{*}{$(95 \% \mathrm{Cl})$} & \multirow[b]{2}{*}{ aHR† } & \multirow[b]{2}{*}{$(95 \% \mathrm{Cl})$} \\
\hline & $\mathbf{N}$ & PY & IR & & & & \\
\hline Non-Haemorrhoids & 349 & 308565 & 1.13 & 1.00 & - & 1.00 & - \\
\hline \multicolumn{8}{|l|}{ Gender } \\
\hline Female & 345 & 166848 & 2.07 & 1.00 & - & 1.00 & - \\
\hline \multicolumn{8}{|l|}{ Age, year } \\
\hline $18-29$ & 85 & 56636 & 1.50 & 1.00 & - & 1.00 & - \\
\hline $30-39$ & 122 & 81659 & 1.49 & 1.00 & (0.76 to 1.32$)$ & 1.05 & (0.79 to 1.38$)$ \\
\hline $40-49$ & 116 & 90231 & 1.29 & 0.85 & (0.64 to 1.13 ) & 0.92 & (0.69 to 1.21$)$ \\
\hline$\geq 50$ & 147 & 157324 & 0.93 & 0.62 & $(0.47 \text { to } 0.81)^{\star \star \star}$ & 0.72 & $(0.54 \text { to } 0.97)^{\star}$ \\
\hline \multicolumn{8}{|l|}{ CAD } \\
\hline Yes & 6 & 9084 & 0.66 & 0.53 & (0.24 to 1.18$)$ & & \\
\hline \multicolumn{8}{|l|}{ Heart failure } \\
\hline No & 459 & 374019 & 1.23 & 1.00 & - & & \\
\hline Yes & 11 & 11831 & 0.93 & 0.74 & (0.41 to 1.35$)$ & & \\
\hline \multicolumn{8}{|l|}{ DM } \\
\hline No & 414 & 341527 & 1.21 & 1.00 & - & & \\
\hline Yes & 56 & 44323 & 1.26 & 1.03 & (0.78 to 1.36$)$ & & \\
\hline \multicolumn{8}{|l|}{ Depression } \\
\hline \multicolumn{8}{|l|}{ Stroke } \\
\hline No & 380 & 285810 & 1.33 & 1.00 & - & 1.00 & - \\
\hline Yes & 90 & 100040 & 0.90 & 0.67 & $(0.53 \text { to } 0.84)^{\star \star \star}$ & 0.79 & (0.60 to 1.03 ) \\
\hline \multicolumn{8}{|l|}{ Hyperlipidaemia } \\
\hline No & 374 & 318869 & 1.17 & 1.00 & - & & \\
\hline Yes & 96 & 66981 & 1.43 & 1.19 & (0.95 to 1.49 ) & & \\
\hline \multicolumn{8}{|l|}{ CKD } \\
\hline No & 450 & 367610 & 1.22 & 1.00 & - & & \\
\hline Yes & 20 & 18240 & 1.10 & 0.88 & (0.56 to 1.37$)$ & & \\
\hline \multicolumn{8}{|l|}{ Constipation } \\
\hline No & 354 & 304702 & 1.16 & 1.00 & - & & \\
\hline Yes & 116 & 81148 & 1.43 & 1.20 & (0.98 to 1.48$)$ & & \\
\hline
\end{tabular}

${ }^{*} \mathrm{p}<0.05,{ }^{* *} \mathrm{p}<0.01,{ }^{* * *} \mathrm{p}<0.001$.

†Adjusted for sex, age, depression and hypertension.

aHR, adjusted HR; CAD, coronary artery disease; cHR, crude HR; CKD, chronic kidney disease; DM, diabetes mellitus; IR, incidence rate per 1000 person-years; PY, person-years. 


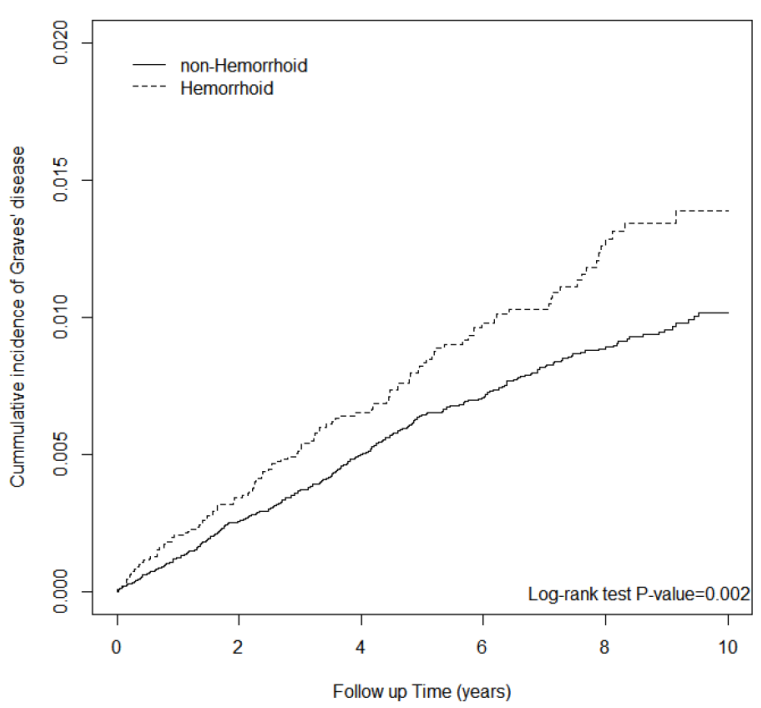

Figure 1 Cumulative incidence of Graves' disease between individuals with and without haemorrhoids.

and that in the control group was 1.13 per 1000 personyears. The incidence curve of GD in patients with haemorrhoids was higher than that of patients without haemorrhoids (figure 1). The risk of GD increased by 1.39 times (95\% CI 1.13 to 1.71 ) in patients with haemorrhoids compared with the non-haemorrhoid patients. Women were more likely to develop GD. Patients older than 50 years had a reduced risk of GD relative to patients with age 18-29. Patients with depression had a higher risk of GD than those without depression (adjusted HR 1.62; $95 \%$ CI 1.57 to 2.70 ).

Table 3 presents the risk of GD in different subgroups. Women with haemorrhoids had a higher risk of GD than women without haemorrhoids (adjusted HR 1.44; 95\% CI 1.13 to 1.83 ). Moreover, patients with haemorrhoids aged 30-39 years were more likely to develop GD than control patients aged 30-39 years (adjusted HR 1.73; 95\% CI 1.18 to 2.55 ). The relationship between the treatment of haemorrhoids and GD is illustrated in table 4. Compared with patients without haemorrhoids and corresponding treatments such as suppositories, constipation-relieving tablets and ointment, the HRs of GD for haemorrhoids patients without the treatments was 1.35 (95\% CI 1.06 to $1.71)$, and that for those with treatments was $1.52(95 \%$ CI 1.07 to 2.15 ).

\section{DISCUSSION}

Our data revealed that the risk of GD was 1.39 times higher in participants with haemorrhoids than in those without haemorrhoids. Additionally, follow-up analysis indicated that younger patients $(<50$ years $)$, women, and patients with depression had a higher risk of GD, which is consistent with current knowledge.

GD, an AITD, is characterised by specific symptoms and signs of overt hyperthyroidism, including weight loss, heat intolerance, fatigue, palpitations, anxiety, and hyperdefecation. ${ }^{8}$ It is also often associated with cardiac valve abnormalities, pulmonary arterial hypertension and autoimmune cardiomyopathy and has a long-term risk of increased hospitalisation due to cardiovascular disorders. ${ }^{15} 16$ Risk factors for haemorrhoids include obesity, depressive mood, stress, poor-fibre diet, constipation, chronic diarrhoea, increased intra-abdominal pressure, prolonged forceful valsalva defecation and history of pregnancy. ${ }^{4}{ }^{17}$ Population-based studies have indicated that haemorrhoids are also associated with peripheral arterial occlusive disease and coronary heart disease. ${ }^{18} 19$ By considering these findings and those of our previous study, ${ }^{14}$ we performed a large database study to evaluate the association between haemorrhoids and GD. Although no direct pathophysiological mechanism linking the two has been identified, future studies should attempt to evaluate relevant gastrointestinal, cardiovascular and psychological factors.

In the subgroup analysis in table 3 , higher risks in various subgroups with haemorrhoids diagnosis were noted, especially in women and patients aged 30-39 years, which are also the potential risk factors for GD. Our analysis indicates that haemorrhoids, irrespective of treatment status, seemed to increase GD risk; however, the definite mechanism behind this phenomenon remains unclear.

Our previous study based on a similar population and study design found an increased risk of Hashimoto's thyroiditis in patients with haemorrhoids. ${ }^{14}$ AITD is a complex disease spectrum without a clear aetiology; two major AITDs are GD and Hashimoto's thyroiditis, which have been the targets of our current and previous studies, respectively. A study revealed that the aetiology of AITD is multifactorial, including multiple genetic and environmental factors; environmental triggers, including dietary iodine, smoking, infections, stress and some medications, contribute to approximately $20 \%$ of GD risk. ${ }^{20}$ The genetic-environmental interaction involved in AITD remains unknown. ${ }^{21}$ Our studies have indicated that haemorrhoid is associated with a significantly increased risk of AITD. Both diseases have common risk factors of stressful lifestyle and depression, which can cause stress to the immune system. Accordingly, a possible mechanism linking the two may be that haemorrhoids stresses the immune system and potentiates its activity against normal tissues, leading to AITD. A prospective study from Denmark involving 145217 patients found that depression is associated with an increased risk of various autoimmune diseases. ${ }^{22}$ Despite the lack of reasonable and credible molecular or genetic explanation for these findings, the significance in the statistical finding is non-negligible; further research should elucidate the aetiology behind the findings.

This study has several limitations. First, data for haemorrhoids, GD, and other comorbidities were retrieved only from the ICD-9-CM codes, which are input by the doctor without strict surveillance. Second, we could 
Table 3 Stratification analysis of haemorrhoids and Graves' disease

\begin{tabular}{|c|c|c|c|c|c|c|c|c|c|c|}
\hline \multirow[b]{2}{*}{ Variables } & \multicolumn{3}{|c|}{ Non-Haemorrhoids } & \multicolumn{3}{|c|}{ Haemorrhoids } & \multirow[b]{2}{*}{ cHR } & \multirow[b]{2}{*}{$(95 \% \mathrm{Cl})$} & \multirow[b]{2}{*}{ aHR† } & \multirow[b]{2}{*}{$(95 \% \mathrm{Cl})$} \\
\hline & $\mathbf{N}$ & PY & IR & $\mathbf{N}$ & PY & IR & & & & \\
\hline \multicolumn{11}{|l|}{ Gender } \\
\hline Female & 254 & 133785 & 1.90 & 91 & 33063 & 2.75 & 1.45 & $(1.14 \text { to } 1.84)^{\star \star}$ & 1.44 & $(1.13 \text { to } 1.83)^{\star \star}$ \\
\hline Male & 95 & 174780 & 0.54 & 30 & 44222 & 0.68 & 1.25 & (0.83 to 1.88$)$ & 1.25 & (0.83 to 1.88$)$ \\
\hline \multicolumn{11}{|l|}{ Age, year } \\
\hline $18-29$ & 65 & 45340 & 1.43 & 20 & 11296 & 1.77 & 1.23 & (0.75 to 2.04$)$ & 1.24 & (0.75 to 2.04$)$ \\
\hline $30-39$ & 85 & 65215 & 1.30 & 37 & 16445 & 2.25 & 1.73 & $(1.18 \text { to } 2.55)^{\star \star}$ & 1.73 & $(1.18 \text { to } 2.55)^{\star \star}$ \\
\hline $40-49$ & 85 & 71986 & 1.18 & 31 & 18245 & 1.70 & 1.44 & (0.95 to 2.17 ) & 1.44 & (0.95 to 2.17 ) \\
\hline$\geq 50$ & 114 & 126023 & 0.90 & 33 & 31301 & 1.05 & 1.17 & (0.79 to 1.72$)$ & 1.16 & (0.79 to 1.71$)$ \\
\hline \multicolumn{11}{|c|}{ Comorbidities } \\
\hline \multicolumn{11}{|l|}{ CAD } \\
\hline No & 345 & 301668 & 1.14 & 119 & 75098 & 1.58 & 1.39 & $(1.13 \text { to } 1.71)^{\star *}$ & 1.39 & $(1.13 \text { to } 1.71)^{\star \star}$ \\
\hline Yes & 4 & 6897 & 0.58 & 2 & 2187 & 0.91 & 1.55 & (0.28 to 8.47$)$ & 1.35 & (0.24 to 7.47 ) \\
\hline \multicolumn{11}{|c|}{ Heart failure } \\
\hline No & 341 & 299400 & 1.14 & 118 & 74619 & 1.58 & 1.39 & $(1.13 \text { to } 1.71)^{\star \star}$ & 1.39 & $(1.13 \text { to } 1.71)^{\star \star}$ \\
\hline Yes & 8 & 9164 & 0.87 & 3 & 2667 & 1.13 & 1.27 & (0.34 to 4.80 ) & 1.23 & (0.33 to 4.65$)$ \\
\hline \multicolumn{11}{|l|}{ DM } \\
\hline No & 305 & 273427 & 1.12 & 109 & 68100 & 1.60 & 1.44 & $(1.15 \text { to } 1.79)^{\star *}$ & 1.44 & $(1.16 \text { to } 1.79)^{\star \star}$ \\
\hline Yes & 44 & 35137 & 1.25 & 12 & 9185 & 1.31 & 1.05 & (0.55 to 1.98$)$ & 1.01 & (0.53 to 1.91$)$ \\
\hline \multicolumn{11}{|c|}{ Depression } \\
\hline No & 302 & 289116 & 1.04 & 106 & 72045 & 1.47 & 1.41 & $(1.13 \text { to } 1.76)^{\star \star}$ & 1.42 & $(1.14 \text { to } 1.77)^{\star \star}$ \\
\hline Yes & 47 & 19449 & 2.42 & 15 & 5240 & 2.86 & 1.19 & (0.66 to 2.12 ) & 1.19 & (0.67 to 2.13 ) \\
\hline \multicolumn{11}{|l|}{ Stroke } \\
\hline No & 324 & 284909 & 1.14 & 112 & 70744 & 1.58 & 1.39 & $(1.12 \text { to } 1.73)^{\star \star}$ & 1.40 & $(1.13 \text { to } 1.73)^{\star \star}$ \\
\hline Yes & 25 & 23656 & 1.06 & 9 & 6541 & 1.38 & 1.31 & (0.61 to 2.80 ) & 1.21 & (0.56 to 2.60$)$ \\
\hline \multicolumn{11}{|c|}{ Hypertension } \\
\hline No & 277 & 228657 & 1.21 & 103 & 57153 & 1.80 & 1.49 & $(1.19 \text { to } 1.87)^{\star \star \star}$ & 1.49 & $(1.19 \text { to } 1.87)^{\star \star \star}$ \\
\hline Yes & 72 & 79907 & 0.90 & 18 & 20133 & 0.89 & 0.99 & (0.59 to 1.66$)$ & 0.98 & (0.58 to 1.64$)$ \\
\hline \multicolumn{11}{|c|}{ Hyperlipidaemia } \\
\hline No & 276 & 255176 & 1.08 & 98 & 63693 & 1.54 & 1.42 & $(1.13 \text { to } 1.79)^{\star \star}$ & 1.43 & $(1.13 \text { to } 1.80)^{\star *}$ \\
\hline Yes & 73 & 53389 & 1.37 & 23 & 13593 & 1.69 & 1.24 & (0.78 to 1.98$)$ & 1.21 & (0.76 to 1.94$)$ \\
\hline \multicolumn{11}{|l|}{ CKD } \\
\hline No & 334 & 294382 & 1.13 & 116 & 73228 & 1.58 & 1.40 & $(1.13 \text { to } 1.73)^{\star \star}$ & 1.40 & $(1.13 \text { to } 1.73)^{\star \star}$ \\
\hline Yes & 15 & 14182 & 1.06 & 5 & 4057 & 1.23 & 1.16 & (0.42 to 3.18 ) & 1.07 & (0.39 to 2.97 ) \\
\hline \multicolumn{11}{|c|}{ Constipation } \\
\hline No & 258 & 243731 & 1.06 & 96 & 60970 & 1.57 & 1.49 & $(1.18 \text { to } 1.88)^{\star \star \star}$ & 1.49 & $(1.18 \text { to } 1.89)^{\star \star \star}$ \\
\hline Yes & 91 & 64833 & 1.40 & 25 & 16315 & 1.53 & 1.09 & (0.70 to 1.70$)$ & 1.08 & (0.69 to 1.68$)$ \\
\hline
\end{tabular}

${ }^{* *} p<0.01,{ }^{* \star *} p<0.001$.

†Adjusted for sex, age, depression and hypertension.

aHR, adjusted HR; CAD, coronary artery disease; cHR, crude HR; CKD, chronic kidney disease; DM, diabetes mellitus; IR, incidence rate per 1000 person-years; PY, person-years.

not obtain certain critical parameters such as results of thyroid function test, thyroid-stimulating immunoglobulin levels, presence of Graves ophthalmopathy, thyroid ultrasound reports and grades of haemorrhoids because of restrictions or unavailability of the relevant information in the database. Finally, potential confounders like coronary artery disease, constipation, diabetes and depression were discussed in our study, yet other unmeasured confounding factors were still not identified. 
Table 4 Relationship between haemorrhoid treatments and Graves' disease

\begin{tabular}{|c|c|c|c|c|c|c|c|c|}
\hline \multirow[b]{2}{*}{ Haemorrhoids } & \multirow[b]{2}{*}{ Drug } & \multicolumn{3}{|c|}{ Graves' disease } & \multirow[b]{2}{*}{ cHR } & \multirow[b]{2}{*}{$(95 \% \mathrm{Cl})$} & \multirow[b]{2}{*}{ aHR† } & \multirow[b]{2}{*}{$(95 \% \mathrm{Cl})$} \\
\hline & & $\mathbf{N}$ & PY & IR & & & & \\
\hline No & No & 349 & 308565 & 1.13 & 1.00 & - & 1.00 & - \\
\hline Yes & Yes & 35 & 20982 & 1.67 & 1.49 & $(1.06 \text { to } 2.12)^{*}$ & 1.52 & $(1.07 \text { to } 2.15)^{\star}$ \\
\hline
\end{tabular}

${ }^{*} \mathrm{p}<0.05$

†Adjusted for sex, age, depression and hypertension.

aHR, adjusted HR; cHR, crude HR; IR, incidence rate per 1000 person-years; PY, person-years.

\section{CONCLUSION}

Patients with haemorrhoids may have an increased risk of GD within 10 years of diagnosis. However, further rigorous laboratory research is required to elucidate the mechanism underlying this association.

\section{Author affiliations}

${ }^{1}$ Department of Family Medicine, Taichung Armed Forces General Hospital, Taichung, Taiwan

${ }^{2}$ Department of Internal Medicine, Asia University Hospital, Taichung, Taiwan ${ }^{3}$ Chung Shan Medical University, Taichung, Taiwan

${ }^{4}$ Management Office for Health Data, China Medical University Hospital, Taichung, Taiwan

${ }^{5}$ College of Medicine, China Medical University, Taichung, Taiwan

${ }^{6}$ Graduate Institute of Biomedical Sciences, College of Medicine, China Medical University, Taichung, Taiwan

${ }^{7}$ Department of Nuclear Medicine and PET Center, China Medical University Hospital, Taichung, Taiwan

${ }^{8}$ Center of Augmented Intelligence in Healthcare, China Medical University Hospital, Taichung, Taiwan

${ }^{9}$ Department of Bioinformatics and Medical Engineering, Asia University, Taichung, Taiwan

Contributors Conception and design: S-RZ, H-HC, H-TY and C-HK; Administrative support: H-TY and C-HK; Collection and data assembly: S-RZ, H-HC, H-TY and C-HK; Data analysis and interpretation: S-RZ, H-HC, H-TY, C-HK; Manuscript writing S-RZ, H-HC, C-CL, C-HS, H-TY and C-HK; Final approval of manuscript: S-RZ, H-HC, $\mathrm{C}-\mathrm{CL}, \mathrm{C}-\mathrm{HS}, \mathrm{H}-\mathrm{TY}$ and $\mathrm{C}-\mathrm{HK}$. C-HK is responsible for the overall content as the guarantor.

Funding This study is supported in part by Taiwan Ministry of Health and Welfare Clinical Trial Center (MOHW110-TDU-B-212-124004), China Medical University Hospital (DMR-110-089, DMR-111-090, DMR-111-091); Ministry of Science and Technology (MOST 110-2321-B-039-003).

Disclaimer The funders had no role in the study design, data collection and analysis, the decision to publish, or preparation of the manuscript. No additional external funding was received for this study.

Competing interests None declared.

Patient and public involvement Patients and/or the public were not involved in the design, or conduct, or reporting, or dissemination plans of this research.

Patient consent for publication Not applicable.

Ethics approval This study was approved to fulfill the condition for exemption by the Institutional Review Board (IRB) of China Medical University (CMUH104-REC2115-AR4). The IRB also specifically waived the consent requirement.

Provenance and peer review Not commissioned; externally peer reviewed.

Data availability statement Data may be obtained from a third party and are not publicly available. The dataset used in this study is held by the Taiwan Ministry of Health and Welfare (MOHW). The Ministry of Health and Welfare must approve our application to access this data. Any researcher interested in accessing this dataset can submit an application form to the Ministry of Health and Welfare requesting access. Please contact the staff of MOHW (email: stcarolwu@mohw.gov.tw) for further assistance. Taiwan Ministry of Health and Welfare Address: No.488, Sec. 6,
Zhongxiao E. Rd., Nangang Dist., Taipei City 115, Taiwan (R.0.C.). Phone: +886-28590-6848. All relevant data are within the paper.

Open access This is an open access article distributed in accordance with the Creative Commons Attribution Non Commercial (CC BY-NC 4.0) license, which permits others to distribute, remix, adapt, build upon this work non-commercially, and license their derivative works on different terms, provided the original work is properly cited, appropriate credit is given, any changes made indicated, and the use is non-commercial. See: http://creativecommons.org/licenses/by-nc/4.0/.

\section{ORCID iDs}

Chun-Cheng Liao http://orcid.org/0000-0002-7508-6297

Chia-Hung Kao http://orcid.org/0000-0002-6368-3676

\section{REFERENCES}

1 Jo SY, Park H, Lee BK, et al. Prevalence of and risk factors for diseases in Korean Americans and native Koreans undergoing health checkup. Korean J Fam Med 2019;40:388-94.

2 Riss S, Weiser FA, Schwameis K, et al. The prevalence of hemorrhoids in adults. Int J Colorectal Dis 2012;27:215-20.

3 Lohsiriwat V. Treatment of hemorrhoids: a coloproctologist's view. World J Gastroenterol 2015;21:9245-52.

4 Ravindranath GG, Rahul BG. Prevalence and risk factors of hemorrhoids: a study in a semi-urban centre. International Surgery Journal 2018;5:496-9.

5 Ekici U, Kartal A, Ferhatoglu MF. Association between hemorrhoids and lower extremity chronic venous insufficiency. Cureus 2019;11:e4502.

6 Sun Z, Migaly J. Review of Hemorrhoid disease: presentation and management. Clin Colon Rectal Surg 2016;29:22-9.

7 Yang JY, Peery AF, Lund JL, et al. Burden and cost of outpatient hemorrhoids in the United States employer-insured population, 2014. Am J Gastroenterol 2019;114:798-803.

8 Burch HB, Cooper DS. Management of Graves disease: a review. JAMA 2015;314:2544-54.

9 Smith TJ, Hegedüs L. Graves' Disease. N Engl J Med 2016;375:1552-65.

10 Prummel MF, Wiersinga WM. Smoking and risk of Graves' disease. JAMA 1993;269:479-82.

11 Ferrari SM, Fallahi P, Ruffilli I, et al. The association of other autoimmune diseases in patients with Graves' disease (with or without ophthalmopathy): review of the literature and report of a large series. Autoimmun Rev 2019;18:287-92.

12 Taylor PN, Albrecht D, Scholz A, et al. Global epidemiology of hyperthyroidism and hypothyroidism. Nat Rev Endocrinol 2018:14:301-16.

13 Furszyfer J, Kurland LT, McConahey WM, et al. Graves' disease in Olmsted County, Minnesota, 1935 through 1967. Mayo Clin Proc 1970;45:636-44.

14 Hsu S-P, Chen H-H, Wang T-Y, et al. Association of hemorrhoids with Hashimoto's thyroiditis and associated comorbidities: a nationwide population-based cohort study. Front Endocrinol 2020;11:577767.

15 Nyirenda MJ, Clark DN, Finlayson AR, et al. Thyroid disease and increased cardiovascular risk. Thyroid 2005;15:718-24.

16 Biondi B, Kahaly GJ. Cardiovascular involvement in patients with different causes of hyperthyroidism. Nat Rev Endocrinol 2010;6:431-43.

17 Lee J-H, Kim H-E, Kang J-H, et al. Factors associated with hemorrhoids in Korean adults: Korean National health and nutrition examination survey. Korean J Fam Med 2014;35:227-36. 
18 Chang S-S, Sung F-C, Lin C-L, et al. Association between hemorrhoid and risk of coronary heart disease: a nationwide population-based cohort study. Medicine 2017;96:e7662.

$19 \mathrm{Hu} \mathrm{W}-\mathrm{S}$, Lin C-L. Hemorrhoid is associated with increased risk of peripheral artery occlusive disease: a nationwide cohort study. $J$ Epidemiol 2017;27:574-7.
20 Tomer Y, Huber A. The etiology of autoimmune thyroid disease: a story of genes and environment. J Autoimmun 2009;32:231-9.

21 DeGroot LJ, Quintans J. The causes of autoimmune thyroid disease. Endocr Rev 1989:10:537-62.

22 Andersson NW, Gustafsson LN, Okkels N, et al. Depression and the risk of autoimmune disease: a nationally representative, prospective longitudinal study. Psychol Med 2015;45:3559-69. 